\title{
La intención específica en el caso Croacia vs. Serbia: apuntes críticos sobre el fallo de la Corte Internacional de Justicia
}

Jean-Paul Saucier Calderón*

\section{RESUMEN}

Después de haber expuesto los antecedentes históricos del caso y los alegatos de las partes, con énfasis en lo referido a la intención genocida, se proponen unos apuntes críticos al fallo de la Corte respecto de los distintos elementos subjetivos que configuran el delito de genocidio. Asimismo, se pone en cuestión el carácter limitativo del estándar inferencial y su interpretación en el caso Croacia vs. Serbia. Si bien la existencia de una pluralidad de elementos subjetivos en el cas d'espèce no implicaba necesariamente que hubo intención genocida, pareciera que esta pluralidad ha sido tratada de manera inconsistente con los propios dictámenes de la Corte, y de manera cuestionable, de suerte a excluir la posibilidad que exista la intención genocida de manera concurrente a elementos subjetivos no genocidas. Este planteamiento pasa por alto la distinción entre motivo e intención, que ha sido discutida en varias ocasiones por la jurisprudencia de los tribunales penales internacionales y que habría servido de marco conceptual valedero para comprender — aunque parcialmente - la relación entre los distintos elementos subjetivos que se han presentado en este caso. La posición de la Corte respecto a la intención genocida también se observa en la ausencia de una posición clara frente a la realidad plural de la intención, que integra tanto a elementos volitivos como cognoscitivos. Se plantea la posibilidad que la Corte haya adoptado un enfoque más abstracto, mientras que una aproximación que se enfoque en la perpetración de los supuestos actos genocidas habría sido más respetuosa del espíritu y la letra de la Convención.

Palabras clave: Corte Internacional de Justicia, genocidio, intención específica, dolo específico, motivo, dolo, elementos volitivos y cognoscitivos.

\footnotetext{
* Docente de la Facultad de Derecho de la Pontificia Universidad Católica del Perú (PUCP), investigador del Instituto de Estudios Internacionales (IDEI) e investigador asociado del Centro de Estudios en Filosofía y Teoría del Derecho (CEFT) de la PUCP, Lima, Perú. Licenciado en Ciencias Políticas por la Universidad de Ottawa (honours) y licenciado en Common Law y Civil Law por la Universidad McGill (B.C.L./LL.B.). Correo electrónico: jean-paul. sauciercalderon@mail.mcgill.ca
} 


\section{Specific Intent in the Croatia V. Serbia Genocide Case: A Critical Appraisal of the ICJ's Ruling}

\section{Abstract}

After having discussed the case's historical background and the parties' arguments with emphasis on genocidal intent, the author offers critical comments on the ICJ's decision. He calls into question the limitations imposed by the Court's inferential standard and its interpretation in the Croatia v. Serbia case. Although the existence of a plurality of subjective elements in this case did not necessarily entail that there must have been a finding of genocidal intent, it appears that such a plurality has been addressed in a manner that is inconsistent with the Court's case law, and involves excluding the possibility that genocidal intent may exist concurrently with other non-genocidal subjective elements. The Court's position overlooks the distinction between motive and intent that has been discussed on many occasions by international criminal tribunals. That distinction could have offered a valuable framework to understand —at least partially — the interplay between different subjective elements displayed in this case. The Court's questionable position on genocidal intent is also evidenced by its lack of a clear position on the plural reality of intent that encompasses volitional and knowledge elements. Finally, the author engages a discussion on the possibility that the Court has adopted an abstract perspective while an approach focusing on the perpetration of the alleged genocidal acts could have been more respectful of the Convention's spirit and letter.

Key words: International Court of Justice, Genocide, specific intent, motive, intent, volitional and knowledge elements. 
Es sabido que el carácter distintivo ${ }^{1}$ del delito de genocidio gira en torno a la intención específica de «destruir total o parcialmente a un grupo nacional, étnico, racial o religioso, como tal $»^{2}$. Mientras esta intención específica cobra sentido en términos de responsabilidad penal individual, la responsabilidad internacional del Estado por el delito de genocidio plantea varias dudas sobre lo que significa la «intención» de un Estado y sobre todo "cómo» se determina la existencia de dicha intención. Se suma a este, el problema central de la aplicación del alto estándar probatorio para demostrar la intención específica establecido por la Corte Internacional de Justicia en el caso Bosnia y Herzegovina $v$ s. Serbia y Montenegro ${ }^{3}$, en el año 2007. Este estándar, criticado por ciertos autores por ser «imposible» (Zivkovic, 2015, pp. 423-427), llevó al más alto tribunal de la ONU a fallar que no hubo genocidio en el caso sobre la Aplicación de la Convención para la Prevención y la Sanción del Delito de Genocidio (Croacia vs. Serbia $)^{4}$.

Este artículo propone una discusión sobre los alcances y los límites del concepto de dolo específico o intención específica (dolus specialis) de acuerdo a lo resuelto por la Corte Internacional de Justicia, en su fallo del 3 de febrero de 2015. Con este fin, se exponen los antecedentes históricos del caso y los alegatos de las partes, con énfasis en lo referido a la intención genocida, para después dilucidar los elementos de la decisión de la Corte al respecto y ofrecer nuestras observaciones críticas sobre el particular.

\section{Los antecedentes históricos del caso}

Los hechos materia de controversia se remontan a la existencia de la República Federal Socialista de Yugoslavia (RFSY), que estaba conformada por las Repúblicas de Bosnia y Herzegovina, Croacia, Macedonia, Montenegro, Eslovenia y Serbia. Tras el fallecimiento del presidente Josip Broz Tito en 1980, el país enfrentó una crisis económica que duró diez años junto a tensiones étnicas y nacionales, que oponían distintas comunidades yugoslavas.

\footnotetext{
1 Corte Internacional de Justicia. Application of the Convention on the Prevention and Punishment of the Crime of Genocide (Bosnia and Herzegovina v. Serbia and Montenegro). Reports, 2007, p. 43, párr. 188.

2 Naciones Unidas. Convention on the Prevention and Punishment of the Crime of Genocide. De 9 de diciembre de 1948. En: Treaty Series, volumen 78, p. 277, artículo II. Disponible en: http://www.refworld.org/docid/3ae6b3ac0.html, página consultada el 11 de marzo 2016.

3 Idem.

4 Véase: Corte Internacional de Justicia. Application of the Convention on the Prevention and Punishment of the Crime of Genocide (Bosnia and Herzegovina v. Serbia and Montenegro). Reports, 2015.
} 
Hacia principios de 1990, algunas repúblicas persiguieron su independencia de la RFSY 5 . El 27 de abril del 1992, mediante una declaración, se estableció la República Federal de Yugoslavia, como estado sucesor de la República Federal Socialista de Yugoslavia ${ }^{6}$. La misma que debería cumplir todas las obligaciones internacionalmente asumidas por la RFSY. Además, la República Federal de Yugoslavia seguía obligada hacia las organizaciones e instituciones de las cuales, la RFSY era miembro.

El mismo día, la Misión Permanente de Yugoslavia ante las Naciones Unidas envió una nota al Secretario General, en la cual aseguraba la continuidad de la personalidad jurídica de RFSY. La República Federal de Yugoslavia continuaría ejerciendo los derechos y acatando las obligaciones asumidas por la RFSY, incluyendo los derivados de tratados internacionales que RFSY había ratificado o a los que había accedido la RFSY'. La pretensión de la RFY de continuar la personalidad jurídica internacional de la RFSY fue largamente cuestionada por la comunidad internacional ${ }^{8}$.

En el año 2003, la RFY pasó a denominarse «Serbia y Montenegro». Tras consulta popular, la República de Montenegro declaró su independencia el 3 de junio 2006 y posteriormente admitido como miembro de las Naciones Unidas, el 28 de junio de 2006. En virtud de esta independencia, la Corte Internacional de Justicia, en el caso bajo análisis determinó que Montenegro no era parte de este litigio. Por tanto, Serbia fue la única parte demandada en este caso.

\section{La situación en Croacia}

El caso materia de análisis se refiere a hechos ocurridos en el territorio de la República de Croacia, en el marco de la RFSY, en el período comprendido entre los ańos 1991 y 1995. A principios del año 1991, el 78\% de los habitantes de la República de Croacia era de ascendencia croata, mientras que el $12 \%$ pertenecía a la comunidad serbia. Vale recalcar que, una importante proporción de dicha minoría serbia vivía en zona fronterizas con Bosnia y Herzegovina.

\footnotetext{
5 Así, Eslovenia y Croacia declararon su independencia de la RFSY, el 25 de junio de 1991, las mismas que desplegaron sus efectos recién el 8 de octubre de 1991. Así también, Macedonia declaró su independencia el 17 de setiembre de 1991; Bosnia y Herzegovina, el 6 de marzo de 1992. El 22 de mayo de 1992, Croacia, Eslovenia y Bosnia y Herzegovina fueron oficialmente reconocidos como miembros de las Naciones Unidas, mientras que Macedonia, fue reconocida el 8 de abril de 1993.

6 Se realizó mediante la sesión conjunta de la Asamblea de la RFSY, de la Asamblea Nacional de la República de Serbia y de la Asamblea Nacional de la República de Montenegro.

7 Hemos de recalcar que la Corte no llegó a resolver completamente los problemas de índole preliminar en su fallo sobre excepciones preliminares, por lo cual tuvo que fallar al respecto en el fallo de fondo.

8 La Corte Internacional de Justicia, el Consejo de Seguridad, la Asamblea General y varios Estados, inicialmente no reconocieron la pretensión de la RFY de suceder automáticamente la membresía de la RFSY en las Naciones Unidas. Recién tras la carta del presidente Koštunica de la RFY, del 27 de octubre de 2000, solicitando formalmente ser aceptada como miembro, la Asamblea General admitió a la RFY, como miembro de las Naciones Unidas, el 1 de noviembre de 2000.
} 
La minoría serbia se oponía a los proyectos independentistas de la República de Croacia. Dicha tensión se exacerbó cuando representantes electos del Partido Democrático Serbio en Croacia crearon la «Unión de Municipalidades de Dalmacia del Norte y Lika», el 1 de julio de 1990. Posteriormente, el 25 de julio de 1990, se estableció una Asamblea Serbia y un "Consejo Nacional Serbio», órgano ejecutivo de dicha Asamblea. Tales entidades proclamaron representar a los serbios de Croacia, y declararon la soberanía y la autonomía de los serbios de Croacia. El «Consejo» también declaró que se llevaría a cabo un referéndum sobre la cuestión de la autonomía de los serbios de Croacia.

En agosto del mismo año, el Gobierno croata quiso impedir el referéndum, pero la minoría serbia estableció barricadas en las vías de acceso terrestre. El referéndum se llevó a cabo entre el 19 de agosto y el 2 de septiembre de 1990, en donde una importante mayoría expresó su apoyo a la autonomía serbia.

El 21 de diciembre 1990, serbios de las municipalidades de Dalmacia del Norte y de Lika establecieron la "Región Autónoma Serbia de Krajina» (SAO Krajina). Posteriormente, otras dos Regiones Autónomas Serbias fueron instauradas: la SAO de Eslavonia del Este, en febrero 1991, y en agosto, la SAO de Eslavonia del Oeste.

El 22 de diciembre de 1990, el Parlamento Croata aprobó una nueva Constitución. Según lo alegado por Serbia, los serbo-croatas consideraban que dicha Constitución los despojó de derechos fundamentales y también suprimió su estatus de nación constitutiva de Croacia. En el año 1991, la fuerzas armadas de Croacia colisionaron con las fuerzas del SAO Krajina y otros grupos armados. El Ejército Popular Yugoslavo (JNA), que era el ejército de la RFSY, intervino oficialmente para separar los bandos opuestos. Croacia alegó que dicha intervención se hizo más bien, en apoyo a los serbios de Krajina.

En un referéndum llevado a cabo el 12 de mayo 1991 por el SAO Krajina, la mayoría de serbios votó a favor de la anexión de su territorio a Serbia y de permanecer en la República Federal Socialista de Yugoslavia (RFSY). A la semana siguiente, en vía de referéndum, los votantes croatas apoyaron en mayoría su independencia de la RFSY. Croacia declaró su independencia de la RFSY el 25 de junio 1991, y dicha declaración surtió efecto el 8 de octubre de 1991.

En el verano de 1991, se iniciaron hostilidades en Croacia, que se denunciaron como violaciones a la Convención. Según lo sostenido por Croacia, desde septiembre de 1991, el JNA, que desde aquel tiempo era controlado por el Gobierno de la República de Serbia, intervino en las hostilidades contra el Gobierno de Croacia. A fines del año 1991, el JNA y las fuerzas serbias, controlaban un tercio del territorio croata (en las regiones de Eslavonia del Este, Eslavonia del Oeste, Banovina/Banija, Kordun, Lika, y Dalmacia). 
El 19 de diciembre 1991, los serbios del SAO Krajina (que ya estaba compuesto por territorios de Dalmacia, Lika, Kordun y Banovina/Banija) declararon el nacimiento de la «Republika Srpska Krajina» («RSK»). Durante los dos meses siguientes, el SAO de Eslavonia del Este y el SAO de Eslavonia del Oeste se unieron a la RSK.

Las negociaciones a fines de 1991 y principios de 1992, apoyadas por la comunidad internacional y en las cuales participaron los representantes de Croacia, Serbia y la RFSY, desembocaron en el denominado "Plan Vance»" $\mathrm{y}$ en el despliegue de la Fuerza de Protección de las Naciones Unidas (UNPROFOR). Dicho Plan preveía un cese de fuego, la desmilitarización de las partes de Croacia bajo el control de las minorías serbias y las fuerzas de la RFSY, el retorno de refugiados y la creación de condiciones favorables para una solución política permanente del conflicto.

La UNPROFOR operó en la primavera de 1991, en tres áreas protegidas por las Naciones Unidas (UNPA). La UNPA de Eslavonia del Este, de Eslavonia del Oeste y de Krajina. Dichas áreas fueron divididas en cuatro sectores operacionales: Este (Eslavonia del Este), Oeste (Eslavonia de Oeste), Norte y Sur que corresponden a la UNPA de Krajina. Los objetivos de Plan Vance y de la UNPROFOR nunca llegaron a ser completamente alcanzados, porque entre 1992 y la primavera de 1995, la RSK no logró ser desmilitarizada. Las dos partes llevaron a cabo operaciones militares, y no se logró una solución pacífica.

Durante la primavera de 1995, Croacia consiguió establecer control sobre una parte importante de la RSK tras varias operaciones militares. Es así que retomó Eslavonia del Oeste en mayo del mismo año, mediante la operación «Flash», y también el Krajina gracias a la operación "Tormenta». Serbia alegó en su contrademanda que, durante la operación Tormenta también ocurrieron violaciones de la Convención. Después de concluido el Acuerdo de Erdut del 12 de noviembre de 1995, Eslavonia del Este fue gradualmente reintegrada a Croacia, entre 1996 y 1998.

\section{El proceso ante la Corte}

\subsection{La demanda de Croacia}

El 2 de julio de 1999, Croacia presentó demanda contra Serbia, en virtud de la Convención sobre genocidio, por presuntamente haber cometido actos de genocidio entre los años 1991 y 1995. Croacia afirmó que, durante dicho período fue sometida a una ocupación ilícita, en casi un tercio de su territorio por parte de fuerzas serbias (JNA y paramilitares), impulsadas por el objetivo nacionalista de crear

\footnotetext{
9 Inspirado del apellido de Cyrus Vance el emisario especial del secretario general de la ONU para Yugoslavia.
} 
la «Gran Serbia $»^{10}$. Las supuestas actividades genocidas dirigidas contra las personas de origen étnica croata causaron más de 12500 muertes y "graves lesiones a la integridad física y mental a decenas de millares de croatas ${ }^{11}$.

Las alegaciones de Croacia incluyeron supuestos eventos en los cuales «se habría acorralado a hasta 7,700 croatas para detenerlos, someterlos a maltratos, violaciones, y tortura [y traslado] a campos de detención». Además del desplazamiento forzado de más de 550000 refugiados y la destrucción de más de 100000 viviendas y más de 1400 espacios de culto católico. Croacia afirmó que el paradero de más de 850 de sus ciudadanos sigue siendo desconocido hoy ${ }^{12}$.

La demanda de Croacia tenía por objetivo que la Corte Internacional de Justicia encuentre a Serbia internacionalmente responsable por la violación de la Convención sobre Genocidio. Además, Croacia solicitó las siguientes reparaciones: i) Que Serbia cumpla con su obligación de procesar y castigar las personas dentro de su jurisdicción por violaciones a la Convención; ii) Que Serbia coopere en la determinación del paradero de ciudadanos croatas que desaparecieron después del genocidio; iii) Que Serbia restituya toda la propiedad cultural incautada durante el supuesto genocidio; y iv) Que Serbia cumpla con las reparaciones pecuniarias a Croacia que le corresponden en nombre propio, pero también las que se le debe como parens patriae de sus ciudadanos ${ }^{13}$.

\subsection{La contrademanda de Serbia}

La parte demandada, Serbia, reconoció que fueron cometidas atrocidades en contra de croatas durante los hechos violentos que marcaron la disolución de la ex-RFSY. No obstante ello, rechazó categóricamente que dichos crímenes constituyan genocidio, o que cualquier delito alegado de genocidio pueda ser atribuido a lo que es hoy en día el Estado soberano de Serbia.

Serbia presentó una contrademanda contra Croacia, por lo que considera fue una campaña genocida que se llevó a cabo, supuestamente, durante la operación Tormenta en agosto de 1995. Según Serbia, dicha operación militar era más bien una conspiración criminal cuya finalidad era «destruir la parte de grupo nacional y étnico serbio que permanecía en la región de Krajina» ${ }^{14}$. Serbia afirmaba que dicho plan genocida se cristalizó durante una reunión del 31 de julio 1995, en la cual participó el presidente de Croacia

\footnotetext{
10 CR 2014/6, pp. 43-45 (Spero).

11 CR 2014/20, p. 34 (Ní Ghrálaigh)

12 CR 2014/ 6, p. 45 (Spero).

13 CR 2014/21, pp. 40-41 (Crnic-Grotic).

14 CR 2014/16, p. 35 (Obradovic).
} 
y otros altos mandos políticos y militares croatas. El supuesto plan habría sido ejecutado unos cuantos días después, durante la primera semana de agosto de 1995.

Serbia alegó que dicho ataque genocida comenzó con una campaña masiva de bombardeo indiscriminado de ciudades del Krajina, lo que provocó la huida generalizada de más de 150000 refugiados de etnicidad serbia ${ }^{15}$, quienes fueron intencionalmente atacados por fuerzas militares croatas mientras huían de la región de Krajina. El mismo ataque concluyó cuando los militares capturaron las ciudades abandonadas y eliminaron sistemáticamente a los pocos serbios que quedaban. Serbia estimó que más de 1700 serbios fueron asesinados, durante y después de la operación Tormenta ${ }^{16}$ y afirmó que 905 víctimas siguen desaparecidas ${ }^{17}$.

Por su parte, Croacia no negó que la operación Tormenta haya ocurrido, o que haya causado pérdidas dentro de la población serbia de Krajina. Sin embargo, rechazó que las acciones militares croatas puedan calificar como genocidio. Croacia arguyó más bien que, esta operación fue una operación militar legítima, destinada a terminar la ocupación ilícita de su territorio por grupos insurgentes serbios. En todo caso, Croacia señaló que la envergadura y duración limitadas de la operación son insuficientes para calificarla como genocidio.

\subsection{El fallo de la Corte}

La Corte determinó que se realizaron actos que constituyen el actus reus de matanza ${ }^{18} \mathrm{y}$ que causaron lesiones graves a la integridad física o mental de los miembros del grupo ${ }^{19}$ protegido de los croatas. A pesar de ello, la Corte no pudo identificar que esos actos se llevaron a cabo con la intención específica requerida para que constituyan genocidio.

El criterio determinante para inferir el dolus specialis — cuando no hay pruebas directas de este- fue desarrollado por la Corte en el caso de Bosnia y Herzegovina vs. Serbia y Montenegro:

The dolus specialis, the specific intent to destroy the group in whole or in part, has to be convincingly shown by reference to particular circumstances, unless a general plan to that end can be convincingly demonstrated to exist; and for a pattern of conduct to be accepted as evidence of its existence, it would have to be such that it could only point to the existence of such intent ${ }^{20}$.

15 CR 2014/16, p. 35 (Obradovic).

16 CR 2014/17, p. 46 (Obradovic).

17 CR 2014/16, p. 65 (Lukic).

18 Corte Internacional de Justicia. Application of the Convention on the Prevention and Punishment of the Crime of

Genocide (Bosnia and Herzegovina v. Serbia and Montenegro). Reports, 2015, párr. 209-295.

19 Ibid., párr. 296-360.

20 Ibid., párr. 373. 
La Corte, siguiendo el razonamiento de los casos de Martic y Mrksic et al., determinó que el JNA y las fuerzas serbias atacaron y ocuparon las localidades, crearon un clima de miedo y de coerción, y cometieron actos correspondientes al actus reus de genocidio. Esta ocupación terminó con la expulsión de la población croata de las localidades ${ }^{21}$.

La Corte coincide con el criterio del TPIY y estableció la existencia de un patrón de conducta de Serbia, que se observa a partir de agosto de 1991, el mismo que consiste en ataques generalizados del JNA y de la fuerzas serbias en localidades con población croata en varias regiones de Croacia, las cuales siguieron el mismo modus operandi ${ }^{22}$.

La Corte debía determinar la existencia de la intención del JNA y de las fuerzas serbias en la comisión de los actos previstos en los incisos a) y b) del artículo II de la Convención. Para ello, aplicó en gran parte en lo establecido en la jurisprudencia del Tribunal Penal Internacional para la ex Yugoslavia. Según el TPIY, los dirigentes de Serbia y de los serbios en Croacia compartían el objetivo de crear un Estado serbio étnicamente homogéneo. El TPIY determinó que estos actos no fueron cometidos con el intento de destruir a los croatas, sino más bien para expulsarlos de las regiones implicadas para llegar a crear un Estado serbio étnicamente homogéneo. Por lo tanto, la Corte considera que no hubo intención genocida ${ }^{23}$.

Respecto a los eventos de Vukovar y de Ovcara sobre los cuales Croacia puso mucho énfasis, la Corte concluyó que en el caso de Vukovar, se puede razonablemente desprender otra intención de los eventos, que es la de castigar la población de dicha ciudad. La misma conclusión aplica al campo de Ovcara ${ }^{24}$.

La Corte consideró que el desplazamiento forzado de miembros del grupo protegido no puede constituir en sí un acto genocida, conforme al artículo II de la Convención. No obstante ello, el desplazamiento forzado que ocurre en paralelo con actos que califican de genocidio, puede ser indicativo de la existencia del dolo específico. En este caso, tal como ya lo determinó la Corte, los desplazamientos forzados fueron un instrumento de la política serbia para establecer una zona geográfica étnicamente homogénea. Según la Corte, ello no implica intención genocida ${ }^{25}$.

\footnotetext{
Ibid., párr. 203-224.

Ibid., párr. 413-416.

Ibid., párr. 426-428.

Ibid., párr. 430.

5 Ibid. párr. 432-435.
} 
Respecto a Vukovar, la Corte subrayó que el TPIY determinó que el JNA y las fuerzas serbias evacuaron civiles croatas en varias ocasiones. El mismo Tribunal también concluyó que, en ciertos casos, soldados croatas fueron capturados por miembros del JNA y fuerzas serbias, y no fueron ejecutados. La Corte refiere a otros casos en los cuales la oportunidad de destruir croatas no fue aprovechada. Por lo tanto, la Corte concluyó que Croacia no pudo demostrar que los perpetradores de los actos aprovecharon de las oportunidades de destruir el grupo protegido ${ }^{26}$.

En suma, la Corte concluyó que Croacia no demostró que el JNA y las fuerzas serbias cometieron actos genocidas en contra de la población croata, con la intención específica de destruir parcial o totalmente dicho grupo, conforme a lo estipulado en los incisos a) y b) del artículo II de la Convención. Por lo tanto, la demanda fue desestimada en todos su extremos, y la Corte no analizó otras violaciones de la Convención alegadas por Croacia.

En su contrademanda, Serbia alegó que los serbios que escaparon de los ataques de la operación Tormenta en columnas fueron sistemáticamente atacados por la fuerzas croatas. Por otro lado, Croacia argumentó que en ciertos casos las personas que huían del operativo fueron víctimas de fuegos cruzados. Sobre este aspecto, la Corte señaló que si bien existieron tales ataques dirigidos en contra de personas que huyeron en columnas, se pone en duda el carácter sistemático de dichas acciones. Sin embargo, ello fue suficiente para que dichas matanzas califiquen como actus reus genocida en virtud del artículo II (a) ${ }^{27}$.

La Corte reiteró que la Sala de Primera Instancia del TPIY ya había determinado que al menos en cuatro localidades del Krajina, se había demostrado que militares croatas y miembros de fuerzas especiales de policía cometieron actos inhumanos y tratos crueles en contra de serbios, después de la operación Tormenta. Asimismo, calificó estos actos como actus reus genocida en virtud del artículo II (b) de la Convención.

En virtud de lo mencionado, la Corte concluyó que las fuerzas militares y policiales croatas cometieron actos que constituyen los actus reus del genocidio, en virtud de los incisos (a) y (b), del artículo II de la Convención.

Serbia alegó que ciertos fragmentos de las transcripciones de una reunión de la jerarquía militar croata en la isla de Brioni el 31 de julio 1995 demuestran la intención genocida de los altos mandos croatas. Al respecto, después de proceder a un análisis detallado de dichos fragmentos, la Corte determinó que el lenguaje utilizado tenía que ser leído en el contexto de una operación militar. Añadió que el TPIY ha

\footnotetext{
26 Ibid., párr. 428-437.

27 Ibid., párr. 485.
} 
determinado que dichas transcripciones no manifiestan intención de destruir. Como máximo, se podría afirmar que lo dicho en ese encuentro podría evidenciar que la operación militar fomentada en esa reunión buscaba provocar la huida de los serbios de Krajina, pero no su destrucción. Por lo tanto la Corte concluyó que el contenido de la reunión de Brioni no permite inferir intencionalidad genocida.

La Corte reiteró que para que un patrón sistemático permita inferir la intención genocida, esta tiene que ser la única inferencia razonable que se pueda derivar de dicho patrón. En el presente caso, la Corte concluyó que los hechos correspondientes al actus reus genocida no han ocurrido en una escala tal que permitan afirmar que constituyen un patrón de conducta del cual se pueda inferir una intención genocida.

La Corte determinó que los ataques de la operación Tormenta eran exclusivamente dirigidos hacia objetivos militares, y las muertes civiles no fueron causadas intencionalmente; por lo tanto, no se puede considerar que dichos ataques, aunque hayan causado muertes civiles, se encuentren en el ámbito del artículo II (a) de la Convención. Serbia no demostró que se hayan producido matanzas según el sentido del artículo II (a) con la intención de destruir en el marco del ataque de artillería en las localidades de dicha región durante la operación Tormenta en agosto 1995. Por tanto, la Corte desestimó la contrademanda presentada por Serbia ${ }^{28}$.

\section{Apuntes críticos}

La determinación de la existencia del dolus specialis constituye uno de los problemas jurídicos más importantes sobre el fondo de la controversia. En esta sección, en primer lugar, se plantean algunas observaciones críticas respecto al criterio inferencial del dolo específico y a su aplicación por la misma Corte. En segundo lugar se comenta la distinción conceptual entre intención y motivo para considera la posibilidad que esa distinción favorezca un mejor entendimiento de los distintos elementos subjetivos que se han presentado ante la Corte. En tercer lugar, y ahondado la idea según la cual los elementos subjetivos del dolo pueden ser plurales, se comenta la distinción entre elementos volitivos y cognoscitivos a la luz del fallo de la Corte y de la propuesta de la penalista Alicia Gil Gil respecto a la aplicación del dolo eventual al delito de genocidio. Finalmente, veremos que a la luz de todo ello, se puede afirmar que la Corte ha adoptado un enfoque abstracto que la llevó a eludir cierto elementos de análisis de mayor importancia en este caso.

\footnotetext{
28 El mayor desarrollo de la Corte respecto al concepto de intención especifica se hace en torno a la demanda de Croacia, razón por la cual enfocaremos en esa parte del fallo sin referir a la contrademanda.
} 


\subsection{La (supuesta) imposible concurrencia de intenciones}

En el caso de Bosnia vs. Serbia, la Corte estableció el siguiente estándar inferencial para determinar la intención específica:

The dolus specialis, the specific intent to destroy the group in whole or in part, has to be convincingly shown by reference to particular circumstances, unless a general plan to that end can be convincingly demonstrated to exist; and for a pattern of conduct to be accepted as evidence of its existence, it would have to be such that it could only point to the existence of such intent ${ }^{29}$.

Este estándar inferencial, lleva a la necesaria exclusión de la inferencia de intención genocida, cuando hubiere otra intención que se pueda desprender del mismo patrón de conducta, de manera concurrente a la intención genocida. Ello implica que - $-\mathrm{y}$ en ello reside el riesgo- que se podría pasar por alto la responsabilidad de un Estado por el delito de genocidio, si se puede inferir una pluralidad de intenciones (de las cuales una sería la genocida). Todo ello se ha observado en el proceso analítico que ha llevado la Corte a determinar que, la intención de establecer una zona geográfica étnicamente homogénea excluía la intención genocida.

En este caso, la Corte estableció la existencia de un patrón de conducta, que consistió en ataques generalizados del JNA y de las fuerzas serbias en localidades con población mayormente croata, en varias regiones de Croacia, bajo el mismo modus operandi ${ }^{30}$. A fin de determinar si dicho patrón de conducta permitía inferir una intención genocida por parte de Serbia, la Corte analizó el contexto y la oportunidad en que se desarrollaron los actos denunciados como genocidas. Es menester recalcar que la Corte tuvo en mente el conocido estándar inferencial que estableció en el caso de Bosnia y Herzegovina vs. Serbia y Montenegro.

Teniendo en mente dicho estándar, la Corte concluyó que en el cas d'espèce había otra inferencia razonable posible. Esta corresponde a la posibilidad de que los actos estuvieran enmarcados en el patrón de conducta dirigido a expulsar los croatas de las distintas áreas del Krajina, con el propósito de crear un estado étnicamente homogéneo ${ }^{31}$. Ello refiere al concepto de limpieza étnica que la Corte definió como: «rendering an area ethnically homogeneous by using force or intimidation to remove persons of given groups from the area $»^{32}$.

29 Corte Internacional de Justicia. Application of the Convention on the Prevention and Punishment of the Crime of Genocide (Bosnia and Herzegovina v. Serbia and Montenegro). Reports, 2007, párr. 373.

30 Corte Internacional de Justicia. Application of the Convention on the Prevention and Punishment of the Crime of Genocide (Bosnia and Herzegovina v. Serbia and Montenegro). Reports, 2015, párr. 413-416.

31 Ibid., párr. 432-435.

32 Corte Internacional de Justicia. Application of the Convention on the Prevention and Punishment of the Crime of Genocide (Bosnia and Herzegovina v. Serbia and Montenegro). Reports, 2007, párr. 190. 
En el caso de Vukovar y sus alrededores, se trata de un área en la cual la destrucción y los ataques dirigidos hacia los civiles croatas fueron masivos y sistemáticos, de suerte que hasta la Sala de Primera Instancia del TPIY concluyó que el ataque contra los croatas y no serbios de Vukovar fue generalizado y sistemático ${ }^{33}$. Pero como en este caso se encontró que hubo intenciones concurrentes, se excluyó la intención genocida para preferir la intención punitiva. También se podía inferir la intención de castigar los Croatas de Vukovar, inclusive a los que fueron llevados al Campo de Ovcara para ser maltratados, torturados y ejecutados ${ }^{34}$. Estos actos tendrían sustento, según la Corte, en la intención de castigarlos en un sentido militar ${ }^{35}$.

\subsection{Contradicción de la Corte respecto a la concurrencia de la intención genocida con la de limpiar étnicamente}

Vale recalcar que la limpieza étnica no está tipificada en el derecho penal internacional, y tampoco conlleva consecuencias jurídicas en el contexto de la Convención, salvo si lo actos de limpieza étnica corresponden objetiva y subjetivamente al tipo de genocidio. Como lo evidencia claramente la siguiente cita, la misma Corte ha asentado que es posible que un conjunto de hechos evidencie paralelamente actos genocidas y de limpieza étnica. Va de suyo que esta afirmación implica también que otra intención (la de limpiar étnicamente) exista de manera concurrente a la intención genocida.

It can only be a form of genocide within the meaning of the Convention, if it corresponds to or falls within one of the categories of acts prohibited by Article II of the Convention. Neither the intent, as a matter of policy, to render an area "ethnically homogeneous», nor the operations that may be carried out to implement such policy, can as such be designated as genocide: the intent that characterizes genocide is «to destroy, in whole or in part» a particular group, and deportation or displacement of the members of a group, even if effected by force, is not necessarily equivalent to destruction of that group, nor is such destruction an automatic consequence of the displacement. This is not to say that acts described as «ethnic cleansing» may never constitute genocide, if they are such as to be characterized as, for example, «deliberately inflicting on the group conditions of life calculated to bring about its physical destruction in whole or in part», contrary to Article II, paragraph (c), of the Convention, provided such action is carried out with the necessary specific intent (dolus specialis), that is to say with a view to the destruction of the group, as distinct from its removal from the region.

\footnotetext{
33 Tribunal Penal Internacional para la Ex Yugoslavia. Prosecutor v. Mrksic et al. (Trial Judgment), IT-95-13/1-T, de 27 septiembre de 2007, párr. 472. Esa conclusión quedó incólume en la apelación.

34 Corte Internacional de Justicia. Application of the Convention on the Prevention and Punishment of the Crime of Genocide (Bosnia and Herzegovina v. Serbia and Montenegro). Reports, 2015, párr 430.

35 Ibid., párr. 429-430.
} 
As the ICTY has observed, while «there are obvious similarities between a genocidal policy and the policy commonly known as 'ethnic cleansing'" (Krstic', IT-98-33-T, Trial Chamber Judgment, 2 August 2001, para. 562), yet «[a] clear distinction must be drawn between physical destruction and mere dissolution of a group. The expulsion of a group or part of a group does not in itself suffice for genocide.» (Stakic', IT-9724-T, Trial Chamber Judgment, 31 July 2003, para. 519.) In other words, whether a particular operation described as «ethnic cleansing» amounts to genocide depends on the presence or absence of acts listed in Article II of the Genocide Convention, and of the intent to destroy the group as such. In fact, in the context of the Convention, the term «ethnic cleansing» has no legal significance of its own. That said, it is clear that acts of «ethnic cleansing» may occur in parallel to acts prohibited by Article II of the Convention, and may be significant as indicative of the presence of a specific intent (dolus specialis) inspiring those acts ${ }^{36}$.

La Corte estableció que la limpieza étnica puede ocurrir paralelamente al genocidio, y que también puede ser indicativa de una intención específica genocida ${ }^{37}$. Por lo tanto, un mismo conjunto o patrón de conductas puede configurar elementos subjetivos que apuntan hacia dos tipos de resultados deseados (el genocidio y la limpieza étnica). A pesar de ello, el estándar inferencial planteado en el párrafo 373 del caso Bosnia y Herzegovina vs. Serbia y Montenegro es interpretado de manera restrictiva por la Corte en Croacia vs. Serbia, de suerte a limitar intención genocida a partir de patrones de los cuales esta se desprende, como única inferencia posible. Es difícil conciliar la posibilidad de que actos intencionales de limpieza étnica, no existan de manera concurrente a la intención genocida. Sobre todo, en un patrón de conductas en el cual los actos intencionales de limpieza étnica son un indicador de intención genocida. Esta contradicción surge del fallo en Bosnia y tampoco se evacuó en el caso Croacia vs. Serbia.

La limpieza étnica y el genocidio implican delitos que se configuran de manera compleja, con cierto nivel de organización y suponen un desarrollo o proceso (Manashaw, 2004, p. 303). Por su carácter generalizado o magnitud de amplia escala, tanto el genocidio como la limpieza étnica son susceptibles de dar lugar a patrones de conducta plurívocos que cambian y evolucionan en el tiempo y el espacio (Munivrana Vajda, 2015, pp. 147-169). En esos casos marcados por la pluralidad de intenciones, el estándar inferencial que asentó la Corte pareciera ofrecer al Estado demandado la posibilidad de apuntar hacia cualquier otra intención, para eximirse de responsabilidad en virtud de la Convención.

\footnotetext{
36 Corte Internacional de Justicia. Application of the Convention on the Prevention and Punishment of the Crime of Genocide (Bosnia and Herzegovina v. Serbia and Montenegro). Reports, 2007, párr 190.

37 Idem.
} 
Una intención distinta a la genocida excluirá a esta. Pero el estándar inferencial de la Corte no pretende que elementos subjetivos que no constituyen intención puedan excluir a la intención genocida. Es decir que si se encuentran elementos subjetivos que se puedan inferir del patrón sistemático de conductas pero que no califican como «intención», estos no tendrían por qué excluir a la intención genocida. Al respecto, se plantea que elementos que calificarían como motivos y no cómo intención podrían haber excluido erróneamente la intención especifica. Si bien el concepto de motivo en muchos casos es confundido con la intención por también ser un elemento subjetivo, la jurisprudencia internacional ha distinguido el motivo de la intención. En todo caso, como lo veremos enseguida, la distinción entre motivo e intención ha de ser discutida para un mejor entendimiento de los distintos elementos subjetivos que pueden surgir en un caso de genocidio y su impacto en la determinación de la intención específica de destruir.

\subsection{La relación entre motivo e intención}

La Corte no ha buscado conceptualizar la distinción que existe entre intención y motivo, y por lo tanto tampoco categorizó los elementos volitivos que encontró según la calificación que les corresponde (motivo o intención). En esta sección se expondrá la distinción entre intención y motivo a la luz del derecho penal internacional, para explicar por qué el caso habría ganado en claridad al distinguir el valor jurídico de distintos elementos volitivos identificados en los hechos.

En el caso Blaskic, la Sala de Apelaciones del TPIY propuso una distinción entre motivo e intención de la siguiente manera: «Mens rea is the mental state or degree of fault which the accused held at the relevant time. Motive is generally considered as that which causes a person to act» ${ }^{38}$. En el caso Stakic, la misma Sala del TPIY ofreció precisiones al respecto y afirmó que los motivos son «el objetivo de la operación» ${ }^{39}$. En Jelisic ${ }^{40}$, Kunarac $^{41}$, y Krnojelac ${ }^{42}$, la Sala de Apelaciones del TPIY puntualizó que el motivo personal de un perpetrador puede ser de obtener un beneficio económico, una ventaja política o una forma de poder, pero que ello no excluía la posibilidad

\footnotetext{
38 Tribunal Penal Internacional para la Ex Yugoslavia. Prosecutor v. Tihomir Blaskic (Appeal Judgement), IT-95-14-A, de 29 julio de 2004, párr. 694.

39 Tribunal Penal Internacional para la Ex Yugoslavia. Prosecutor v. Milomir Stakic (Appeal Judgement), IT-97-24-A, de 22 de marzo de 2006, párr 45.

40 Tribunal Penal Internacional para la Ex Yugoslavia. Prosecutor v. Goran Jelisic (Appeal Judgement), IT-95-10-A, 5 de julio de 2001, párr 49.

41 Tribunal Penal Internacional para la Ex Yugoslavia. Prosecutor v. Dragoljub Kunarac, Radomir Kovac and Zoran Vukovic (Trial Judgment), IT-96-23-T \& IT-96-23/1-T, de 22 de febrero de 2001, párr 103 y 153.

42 Tribunal Penal Internacional para la Ex Yugoslavia. Prosecutor v. Milorad Krnojelac (Appeal Judgement), IT-97-25-A, de 17 de setiembre de 2003, párr 102.
} 
de que el perpetrador también tenga la intención específica genocida. En Popovic, la Sala también reafirmo los mismo poniendo énfasis en los motivos de índole militar ${ }^{43}$. En el caso Kayishema y Ruzindana, la Sala de Apelación del TPIR también precisó que la existencia de motivos personales no excluía la posibilidad de que haya dolo ${ }^{44}$. En el caso Tadic, la Sala de Apelaciones del TPIY precisó la irrelevancia de los motivos para el derecho penal, salvo para los fines de la determinación de la pena ${ }^{45}$. Es preciso recordar que en el caso Blaskic, la Sala de Apelaciones recordó que el motivo podía tener relevancia en las situaciones en las cuales había de ser demostrado como en los casos de crímenes de intención específica ${ }^{46}$. Desgraciadamente, la Sala de Apelaciones no explicitó de manera clara por qué y en qué medida los motivos habían de ser demostrados en delitos de intención específica ${ }^{47}$. A pesar de esa afirmación de la Sala de Apelaciones, de manera general se puede afirmar, como lo señala Paul Behrens, que los Tribunales penales internacionales evitan analizar los motivos detrás de un delito, si bien postular el carácter «inescrutable» e irrelevante de los motivos en derecho penal se ha vuelto una suerte de política en los tribunales penales internacionales desde el fallo de apelación del caso Tadic (Behrens, 2012: 505) ${ }^{48}$.

En su estudio crítico del concepto de motivo, Paul Behrens busca aproximarse a dicho concepto mediante un análisis de distintos tipos penales que incluyen explícitamente motivos, como lo que podría denominarse el homicidio con circunstancias agravantes $(M o r d)$ —en el ordenamiento alemán— el cual puede aplicar si se utiliza ciertos métodos para llevar a cabo el homicidio, o si motivos específicos llevan el sujeto a cometer el delito. El estudio de este y otros tipos penales que prevén un motivo, llevan el autor alemán a concluir que:

What these elements have in common is that they describe the purpose that underlies the actus reus (and the formation of mens rea as far as it mirrors the actus reus). As subjective elements they go beyond the 'ordinary' mens rea: they are not part of that mirror image, but lead an existence that has no equivalent on the objective side of the crime (Behrens, 2012, p. 506).

\footnotetext{
43 Tribunal Penal Internacional para la Ex Yugoslavia. Prosecutor v. Vujadin Popovic (Appeal), IT-05-88-A, de 30 de enero de 2015, párr. 733.

44 Tribunal Penal Internacional para la Ex Yugoslavia. The Prosecutor v. Clément Kayishema and Obed Ruzindana (Trial Judgement), ICTR-95-1-T, de 21 de mayo de 1999, párr 161.

45 Tribunal Penal Internacional para la Ex Yugoslavia. Prosecutor v. Dusko Tadic (Appeal Judgement), IT-94-1-A, de 15 de julio de 1999, párr 268-269.

46 Tribunal Penal Internacional para la Ex Yugoslavia. Prosecutor v. Tihomir Blaskic (Appeal Judgement), IT-95-14-A, de 29 julio de 2004, párr. 694.

47 La Sala de Apelaciones se limita a referir a varios casos de Salas de Apelación de TPIs pero los fragmentos citados no sustentan claramente su postura al respecto.

48 Véase también: Tribunal Penal Internacional para la Ex Yugoslavia. Prosecutor v. Dusko Tadic (Appeal Judgement), IT-94-1-A, de 15 de julio de 1999, párr. 268.
} 
Si bien este concepto se deriva del análisis de delitos que prevén explícitamente un motivo, nada se opone conceptualmente a que fundamenten nuestro entendimiento del motivo en contextos en el cual este no hace parte del tipo subjetivo. Este es el caso del delito de genocidio, para el cual la historia de la negociación de la Convención demuestra claramente que se han excluido los motivos de su tipo subjetivo ${ }^{49}$.

A pesar de las distinciones que la jurisprudencia plantea entre motivo e intención, las semejanzas que pueden existir entre ambas en el caso en concreto abogan a favor de considerar los motivos al momento de analizar la aplicación de la Convención para asegurarse de que no se están confundiendo motivo e intención. Lo que queda de esta sección se dedicará a presentar y discutir unos cuantos planteamientos de Behrens respecto a la relación entre motivo e intención de suerte a poner en evidencia ciertos aspectos que puede tomar esa relación.

Un elemento de proximidad que marca la relación entre los dos conceptos se fundamenta en el carácter auxiliar del motivo ante la intención específica. Según Behrens, en el delito de genocidio, la intención primera es la intención de destruir, pero pueden haber varios motivos secundarios (que existen de manera acumulativa o alternativa) detrás de dicho "motivo" principal (que es la intención específica). Por ejemplo, se puede tratar de motivos políticos, económicos, militares, etc., que configuran la intención específica cuya posición puede variar en la "cadena de motivos», pero a pesar de ello, lo importante es que sigue existiendo la intención destructiva. Es decir que aunque la intención de destruir tome una predominancia variable según los motivos involucrados, ello no cambia en nada que el autor tenía la intención de destruir (Behrens, 2012, p. 510). Por ejemplo, en el caso que nos interesa, no habría sido descabellado considerar que en la región de Vukovar se cometieron matanzas con la intención destructiva porque se buscaba castigar a los croatas de esa misma área.

Los motivos no solo tendrían un carácter secundario sino que también podrían ser conceptualizados al mismo nivel que la intención específica. Es decir que, por su importancia, los motivos podrían fundamentar la mens rea y el actus reus genocida, pero no configurarían el dolo específico (Behrens, 2012, p. 510). La jurisprudencia de los tribunales penales internacionales ${ }^{50} \mathrm{y}$ también de la Corte parecen suponer que hay motivos que no se encuentran detrás de la intención específica y que pueden coexistir con la intención genocida. Al respecto, como ya lo advertimos, la Corte Internacional de Justicia afirmó en Bosnia vs. Serbia que los actos de limpieza étnica pueden constituir genocidio

49 Naciones Unidas. Official Records of the Third Session of the General Assembly, Part I. Legal Questions, Sixth Committee. Summary Records of Meetings, 21 de setiembre - 10 de diciembre de 1948. Doc. A/C.6/SR.75, p. 118.

50 Tribunal Penal Internacional para la Ex Yugoslavia. Prosecutor v. Goran Jelisic (Appeal Judgement), IT-95-10-A, 5 de julio de 2001, párr. 49. Tribunal Penal Internacional para la Ex Yugoslavia. Prosecutor v. Milorad Krnojelac (Appeal Judgement), IT-97-25-A, de 17 de setiembre de 2003, párr. 102. 
y también pueden ser cometidos de manera paralela a los actos de genocidio ${ }^{51}$. Por ello, la intención específica de destruir podría existir al mismo tiempo que la motivación de limpiar étnicamente una zona geográfica, es decir, no serían excluyentes.

Si bien no parece existir una necesidad conceptual de que solo se pueda derivar una intención de un conjunto de conductas para que se concluya la existencia de genocidio, la Corte ha decidido claramente en ese sentido. Ello no niega que puedan existir elementos subjetivos que se encuentren a varios niveles como lo evidencia la relación auxiliar que puede tener el motivo ante la intención. De haber tomado en cuenta la posibilidad de que existan otros elementos volitivos detrás de la intención específica, es posible que, por ejemplo, se haya considerado que la destrucción en Vukovar y sus alrededores se haya llevado a cabo con la intención específica de destruir a los croatas de esa zona, y con la motivación (el porqué) de castigarlos y de establecer el poderío de Serbia sobre la RFSY ante todas las otras Repúblicas. No se pretende que la Corte habría necesariamente concluido que había intención específica, sino que es una posibilidad que no contempló: solo aceptó la posibilidad de que existan elementos subjetivos del mismo nivel, y que, si un elemento subjetivo existiere concurrentemente a la intención genocida, esta habrá de ser negada.

Esa supuesta imposibilidad de que haya un dolo concurrente (u otro elemento subjetivo) al dolo genocida apunta hacia una manera de conceptualizar el dolo que se limita a una consideración de los elementos subjetivos de "primer nivel», diría Behrens. Es decir se niega la posibilidad que haya elementos subjetivos (como el motivo) detrás del dolo específico, lo que implica el riesgo de confundir motivos con intención que son elementos que han sido claramente distinguidos por la doctrina y la jurisprudencia internacional. Ese razonamiento restrictivo no es ajeno al silencio de la Corte respecto a la posibilidad de que un perpetrador de genocidio, si bien no tenía la voluntad directa de destruir, no desconocía la probable realización de la destrucción. Se trata de la posibilidad de que la intención genocida se pueda concretar por dolo eventual. Veremos enseguida lo valioso y lo esclarecedor que habría sido una decisión que hubiera tomado en cuenta cómo pueden operar los elementos subjetivos del dolo que son la voluntad y el conocimiento.

\subsection{El dolo eventual y genocidio: ¿̇saber o solo querer?}

En esta sección se aborda la posibilidad de que el delito de genocidio sea cometido con dolo eventual. Este ejercicio conceptual tiene la virtud didáctica de demostrar en qué medida el dolo tiene una dimensión plural que no ha sido tomada en cuenta

\footnotetext{
51 Corte Internacional de Justicia. Application of the Convention on the Prevention and Punishment of the Crime of Genocide (Bosnia and Herzegovina v. Serbia and Montenegro). Reports, 2007, párr. 190.
} 
por la Corte en su fallo. Aunque nuestro Código Penal no prevé una definición del dolo, este es definido por la doctrina y la jurisprudencia como el «conocimiento y voluntad de la realización de todos los elementos del tipo objetivo y es el núcleo de los hechos punibles dolosos» (Villavicencio Terreros, 2013, p. 354) ${ }^{52}$. El planteamiento de los elementos cognoscitivos y volitivos del dolo también se encuentra presente en el Derecho Penal Internacional, en el artículo 30 del Estatuto de Roma que planteó los siguientes elementos que fundamentan el concepto del dolo: la «intención y conocimiento de los elementos materiales del crimen».

Tal como lo precisa Villavicencio Terreros, hay tres clases de dolo: el dolo directo de primer grado (inmediato) el dolo directo de segundo grado (dolo mediato) y el dolo eventual. El dolo directo de primer grado enfoca en el aspecto volitivo del autor, pues se trata del dolo que expresa la voluntad del autor que corresponde al tipo objetivo, por lo tanto, el aspecto cognoscitivo revierte menor importancia para el dolo directo (2013, p. 369). En cuanto al dolo directo de segundo grado, se trata más bien de un dolo en el cual el autor desea un resultado específico, del cual fluyen otras consecuencias necesarias o inevitables. En este caso el elemento cognoscitivo domina, pues la cuestión gira en torno al conocimiento de la vinculación de la consecuencia «secundaria» con la consecuencia deseada por el autor (2013, pp. 371-372). En fin, el dolo eventual, que es objeto de varias controversias doctrinales, se ha conceptualizado alrededor de, entre otras, la teoría del consentimiento y la de la probabilidad. La teoría del consentimiento pone énfasis en el elemento volitivo, pues supone que para que se configure el dolo eventual es suficiente con que el autor haya aceptado que los resultados sean posibles, es decir tiene que «aprobarlos interiormente ${ }^{53}$. Por otro lado, se encuentra la teoría de la probabilidad (o representación) que más bien se enfoca en un aspecto cognoscitivo, estableciendo que el dolo eventual depende del grado de probabilidad que se ha representado el autor, respecto a la producción del resultado ${ }^{54}$.

Varias versiones de la teoría ofrecen distintos niveles de probabilidad representados, entre los cuales vale recalcar, con Jakobs, el criterio de la no improbable producción del resultado. Esta supone que para que el autor tenga dolo eventual, este tiene que considerar la no improbabilidad del resultado de su conducta ${ }^{55}$. Villavicencio Terreros precisa que la posición dominante de la doctrina acepta más bien que el dolo eventual supone que el «autor considera seriamente la realización del tipo y se conforma con ella ${ }^{56}$.

Véase también: Ejecutoria Suprema del 26 de marzo de 1998. Expediente 455-97, Callao.

Ibid., párr. 790-792.

4 Ibid., párr. 793.

55 Ibid., pár. 794-795.

56 Ibid., párr. 796. 
Vale recalcar que en el ordenamiento peruano, en el caso Utopía, la Corte Suprema concurrió con la posición de la doctrina mayoritaria a la cual refiere Villavicencio Terreros y precisa los criterios necesarios para que se configure el dolo eventual:

(I) Un conocimiento de la capacidad concreta de la conducta para generar un resultado típico; (II) La producción del resultado típico debe evaluarse dentro del contexto de un aumento al riesgo permitido; (III) Dicho conocimiento no debe implicar una evaluación estadística, por parte del agente, de la probabilidad de daño, por las objeciones mencionadas anteriormente; (IV) Se trata de evaluar en la situación concreta y con relación al agente, si su pronóstico concreto lo llevaba a la convicción de que no se produciría el resultado típico; (V) Lo que diferencia, dentro de esta línea de análisis, al dolo eventual de la culpa consciente es que en el primer caso el agente considera seriamente la probabilidad del resultado dańoso, aceptando necesariamente dicha probabilidad con la realización de la conducta peligrosa, per se, o por otra persona. En la culpa consciente existe por el contrario la creencia de que el peligro no va concretarse; (VI) Finalmente, es de señalar que la "aceptación» a la que se alude en el dolo eventual, en los términos aquí planteados, no se refieren a la aceptación del resultado dańoso (por ejemplo, producción de muertes o lesiones a las personas), sino únicamente de la conducta capaz de producirlo ${ }^{57}$.

Esta cita nos permite apreciar que el concepto de dolo eventual aceptado por la jurisprudencia peruana prevé una intensidad volitiva más importante que la propuesta por Jakobs. El estándar de la Corte Suprema supone que el autor tiene que considerar seriamente la probabilidad del resultado, mientras que Jakobs prevé que para satisfacer el dolo eventual, el autor apenas necesita considerar la no improbable producción del resultado. A pesar de ello, vale la pena tener en mente el estándar propuesto por Jakobs ya que su concepto del dolo eventual fundamentó valederos argumentos a favor de la aceptación del dolo eventual en el contexto del dolo genocida.

Alicia Gil Gil plantea el problema de la intensidad volitiva del dolo genocida. Es decir, busca saber si la intención de destruir un grupo tiene que corresponder a un dolo directo o si el dolo eventual es suficiente para hacer esa determinación. Ello tiene implicancias sobre los límites del alcance del tipo subjetivo de genocidio. ¿Puede haber genocidio únicamente en los casos en los cuales la destrucción es la meta directa del perpetrador? o ¿podría también haber intención genocida en supuestos en los cuales el perpetrador no busca directamente la destrucción del grupo? Gil Gil contempla, entre otros, los casos en los cuales la destrucción parcial o total es una consecuencia intrínsecamente relacionada con un objetivo de otra índole (políticos, estratégico, etc.) y en los cuales el perpetrador contempló la destrucción del grupo como resultado no absolutamente improbable de las conductas (1999, p. 232).

57 Véase: Expediente. No 306 2004, Acápite 16. 
La penalista española observa la similitud entre la estructura del delito de genocidio y la tentativa, lo que le permitirá determinar que el tipo subjetivo del genocidio abarca más que el simple dolo directo, y más bien incluye el dolo eventual:

Respecto a la lesión del bien jurídico la estructura (del genocidio) es paralela a la de una tentativa acabada, ya que se han comenzado los actos ejecutivos, pero el delito se consuma formalmente con el menoscabo (la muerte, la destrucción) de una parte ínfima (un individuo) del objeto material del bien jurídico (dicho objeto estaría formado por el conjunto de todos los individuos que forman el grupo o subgrupo seleccionado por el elemento subjetivo), lo que para dicho bien (la existencia del grupo o subgrupo seleccionado en su conjunto) constituiría todavía únicamente un peligro abstracto.

$[\ldots]$

En los delitos de resultado cortado [...] la estructura valorativa viene a ser paralela a la de una tentativa acabada (delitos de resultado cortado en los que únicamente se prescinde del acaecimiento del resultado) o inacabada (delitos mutilados de varios actos), pues el legislador ha querido otorgar una mayor protección al bien jurídico mediante el adelantamiento de la consumación formal (Gil Gil, 1999, pp. 195 y 238).

Respecto a la intensidad volitiva que requiere la tentativa, la misma autora además de plantear ejemplos en los cuales el tipo subjetivo de la tentativa se puede realizar mediante un dolo eventual, se refiere también a la jurisprudencia y doctrina mayoritaria española que confirman que el dolo eventual puede sustentar una tentativa (Gil Gil, 1999, p. 238). Esta «relajación» de la intensidad volitiva se debería a la voluntad legislativa de ofrecer una amplia protección al bien jurídico implicado:

Para la inclusión del resultado que identifica la lesión del bien jurídico en la voluntad de realización en los delitos mutilados de varios actos basta, igual que en cualquier tentativa inacabada, con un elemento volitivo equivalente al exigido en el dolo eventual, pues [...] el objetivo del legislador no ha sido aquí limitar la protección del bien jurídico, sino por el contrario ampliarla adelantando la consumación (1999, p. 240).

A la luz de los argumentos expuestos, la penalista española concluye que los tipos objetivos de (a) muerte de miembros del grupo, (b) lesiones, (d) impedimento de nacimiento y (e) traslado de nińos a otro grupo, tienen la estructura de tentativa inacabada por ser delitos mutilados de varios actos, que suponen un serie de actos para llegar a lesionar el bien jurídico. En el caso paradigmático de la muerte de los miembros del grupo, por ejemplo, cada muerte es un acto ejecutivo dirigido hacia la destrucción del grupo con la intención de seguir matando miembros del mismo para llegar a dicho fin. Por lo tanto, para que haya dolo genocida, estos tipos objetivos tienen que haberse llevado a cabo con el conocimiento de que los mismos se enmarcan en un plan que incluye un conjunto de actos ejecutivos dirigidos hacia la destrucción del grupo. En el caso de que el autor prevea la destrucción como resultado no absolutamente improbable de la realización de conductas cuyo objetivo primario 
no sea la destrucción (por ejemplo, fines estratégicos, políticos o económicos), y que se consume formalmente el delito (la muerte del miembro del grupo), habrá dolo eventual (Gil Gil, 1999, pp. 232, 258-260).

La aplicación del concepto del dolo eventual para establecer el dolo genocida no es poco controvertida y hemos de subrayar que se trata de una posición doctrinal minoritaria. Autores como Schabas han refutado la aplicación del dolo eventual al genocidio, pues su baja intensidad volitiva difícilmente se ajusta a un crimen de semejante gravedad. A pesar de ello, el mismo autor aboga por un concepto de la intención genocida que abarque elementos cognoscitivos y no exclusivamente volitivos (2009, pp. 254-255).

Kai Ambos, por su parte, ofrece una crítica del concepto tradicional (exclusivamente volitivo) de la intención específica para proponer una visión mixta que incorpora un concepto fundamentado en el elemento cognoscitivo o estructural (knowledge and structure-based approaches) que sería suficiente para los perpetradores de nivel intermedio y bajo en la cadena de mando, mientras que para los altos mandos un concepto volitivo del dolo habrá de seguir aplicando (2009, p. 1). Alexander KA. Greenawalt, plantea que cuando se ha demostrado el actus reus genocida, se cumple con el elemento subjetivo del genocida cuando se puede demostrar que el perpetrador actuó de manera a contribuir a una campaña dirigida contra miembros del grupo protegido y conocía que el objetivo o el resultado de dicha campaña era la destrucción del grupo total o parcialmente (1999, p. 2288).

En fin, Katherine Goldsmith argumenta que el requisito de la intención específica nunca fue previsto explícitamente durante la negociación de la Convención como lo demuestran los Travaux Préparatoires. Las altas exigencias de la intención específica afectarían el rol preventivo de la Convención y por lo tanto la autora propone una posición intermedia entre el dolo general y el dolo específico, de suerte que quien cometa un acto prohibido con el conocimiento de que contribuirá a una ofensiva en curso contra un grupo protegido será responsable de genocidio (2010, p. 254). Vale también recalcar que Goldsmith llega a la conclusión de que si bien el TPIY ha adoptado una postura muy restrictiva respecto al elemento cognoscitivo del dolo, el TPIR ha otorgado más espacio a esa faceta del dolo (lo que se debe probablemente al hecho que en el caso de Ruanda las ocurrencias de genocidio eran mucho más evidentes). Agrega Goldsmith que aunque la Corte Penal Internacional no se ha pronunciado aún sobre el genocidio, se puede pronosticar que habrá de tomar en cuenta el elemento cognoscitivo de la intención específica, pues el artículo 30 del Estatuto de Roma sobre los elementos de la intencionalidad prevé que el elemento subjetivo es constituido por la intención y el conocimiento, y al respecto argumenta que la Corte Penal internacional no ha de considerar la cuestión de la intencionalidad como un tema firmemente establecido (Kress, 2005, p. 578). 
Esta corta incursión en los elementos subjetivos que son las vertientes volitivas, y cognoscitivas de la intención, demuestran una vez más que la Corte ha adoptado una perspectiva unidimensional, que limitó su aprehensión de la realidad subjetiva del genocidio. La propuesta que hace Gil Gil respecto a la aplicación del dolo eventual al genocidio evidencia (aunque de manera un poco extrema) que la integración del aspecto cognoscitivo del dolo puede impactar sobre la determinación del dolo específico. Si bien el desarrollo del derecho penal internacional no apunta hacia tal relajamiento de los requisitos subjetivos del genocidio, tampoco se puede negar que hay una creciente presión doctrinal que apunta hacia la necesidad de abordar el dolo también por la vía del conocimiento para no dejar sin efecto las protecciones establecidas por la Convención. La Corte no ha hecho ninguna referencia a la vertiente cognoscitiva del dolo posiblemente porque en este contexto se trata de un delito, de un contexto histórico y de hechos que han sido exhaustivamente analizados por el TPIY. Si bien las relaciones entre los dos tribunales no son exentas de tensiones jurisprudenciales, es probable que la Corte no ha querido llevar a cabo incursiones muy temerarias en conceptos como el de dolo específico para el cual las jurisdicciones penales son más cualificados. La lectura del fallo Croacia vs. Serbia deja muy claro que la Corte ha sido muy deferencial respecto a los hallazgos del TPIY de suerte que en varios casos las conclusiones del tribunal penal especial se sustituían a las de la Corte ${ }^{58}$. Ello nos lleva a nuestro último punto de discusión que es las limitaciones que implican un análisis mayormente abstracto del delito de genocidio.

\subsection{El genocidio como delito sistemático y abstracto}

Como lo advierte Paul Behrens, los tribunales no penales que se enfrentan al problema del dolo genocida no tienen medios como los tribunales penales para investigarlo y en consecuencia se encuentran ante dos posibles soluciones: delegar la determinación concluyente del dolo a otra autoridad, o enfocar su razonamiento en los elementos del crimen que pueden ser determinados, sin tener que analizar el estado mental de los perpetradores (2015, pp. 923-925). Puesto que la Corte no puede formalmente delegar a otro ente ${ }^{59}$ la determinación del dolo, en este caso, se resolvió enfocando el razonamiento en elementos que le permitieron eludir el análisis del dolo de los perpetradores, en un estudio más abstracto de la intencionalidad genocida que se enfoca en el carácter sistemático del delito de genocidio, perspectiva que un autor como Kirsch denominó un «macro-fenómeno» (2009, p. 347).

\footnotetext{
58 Corte Internacional de Justicia. Application of the Convention on the Prevention and Punishment of the Crime of Genocide (Bosnia and Herzegovina v. Serbia and Montenegro). Reports, 2015, párr. 180-188 y 464-472.

59 A pesar de que formalmente no pueda delegar esas funciones, no cabe duda el grado de deferencia que le otorgó a conclusiones de hecho y de derecho del TPIY.
} 
La noción de "macro-fenómeno" postula una comprensión del genocidio como un delito de configuración sistemática, que supone un plan con una organización que lo respalde ${ }^{60}$. Según lo planteado, una persona no podría, de manera realista, creer que sus acciones aisladas, sin el respaldo de otras acciones, serían capaces de producir la destrucción de un grupo (Kress, 2005, p. 578). Por tanto, el requisito de intención específica del genocidio supondría la necesidad de demostrar dicha intención del perpetrador, con referencia a un contexto genocida al cual se relacionan directamente sus acciones (Kirsch, 2009, p. 360). Por ejemplo, los «Elementos del Crimen» a los que se refiere el artículo 9 del Estatuto de Roma exigen que cada uno de los distintos actos (actus reus) genocidas (que coinciden con la Convención) tienen que haber «tenido lugar en el contexto de una pauta manifiesta de conducta similar dirigida contra ese grupo o haya podido por sí misma causar esa destrucción» (Corte Penal Internacional, 2010).

La práctica judicial de los tribunales penales internacionales también ha respaldado un concepto del genocidio que integra una faz más abstracta: (el contexto) por un lado; y por el otro, la conducta y el dolo específico del perpetrador. Las decisiones de los tribunales penales internacionales sobre genocidio buscan identificar la existencia de genocidio de manera general, para luego enmarcar los hechos pertinentes en ese contexto. Tal como lo afirmó la Sala de Primera Instancia del TPIY, en el caso Jelisic, «it will be very difficult in practice to provide proof of the genocidal intent of an individual if the crimes committed are not widespread and if the crime charged is not backed by an organization or a system ${ }^{61}$. El TPIY reconoce por lo tanto la posibilidad de que pueda ocurrir genocidio sin patrón sistemático pero que la demostración de la intención especifica será muy difícil. Por lo tanto en derecho penal internacional se puede argumentar que si bien se adopta también una perspectiva «macro», se admite también el enfoque del perpetrado.

En el caso que nos interesa, la Corte centró su análisis en el patrón sistemático como base para determinar la intención genocida, lo que determinó que la Corte no encontrara ninguna intención genocida específica, haciendo de tal elemento un factor deci$\operatorname{sivo}^{62}$. Es cierto que el patrón sistemático es un elemento constitutivo del crimen

\footnotetext{
60 Tribunal Penal Internacional para la Ex Yugoslavia. Prosecutor v. Goran Jelisic (Trial Judgement), IT-95-10-T, de 14 de diciembre de 1999, párr. 100.

61 Ibid., párr. 94.

62 Por ejemplo, la parte del análisis sobre la intención especifica del fallo que nos interesa está encabezada por el cuestionamiento respecto al patrón sistemático, véase, por ejemplo, los párrafos 407-439, en los cuales la Corte plantea la pregunta siguiente que determinará la existencia del dolo específico: Is there a pattern of conduct from which the only reasonable inference to be drawn is an intent of the Serb authorities to destroy, in part, the protected group?» Corte Internacional de Justicia. Application of the Convention on the Prevention and Punishment of the Crime of Genocide (Bosnia and Herzegovina v. Serbia and Montenegro). Reports, 2015.
} 
de genocidio en virtud de los «Elementos del Crimen» plasmados en el Estatuto de Roma. Pero la Corte no ha fallado en virtud del Estatuto de Roma, sino que su competencia se limita a aplicar e interpretar la Convención. Al respecto, el juez Gaja, mediante su voto singular, puntualizó que los «Elementos del Crimen» han sido determinados unos 50 años después de la Convención, pero no sabrían constituir un "acuerdo ulterior entre las partes acerca de la interpretación del tratado» en virtud del artículo 31(3)(a) de la Convención de Viena sobre el derecho de los Tratados (Behrens, 2015, p. 927) ${ }^{63}$. Tanto la Convención como sus travaux préparatoires parecen plantear de manera exclusiva el genocidio como delito perpetrado por personas, sin poner énfasis en su carácter sistemático. Al respecto, en el caso Jelisic del TPIY, la Sala de Primera instancia, al analizar el dolo específico del acusado a la luz de la Convención, afirmó que: «the drafters of the Convention did not deem the existence of an organization or a system serving a genocidal objective as a legal ingredient of the crime. In so doing, they did not discount the possibility of a lone individual seeking to destroy a group as such ${ }^{64}$.

La introducción del requisito de sistematicidad por la Corte en su análisis de la intención — que ya se asentó desde que falló en el caso Bosnia- es criticable por no tener fundamento en la Convención (Behrens, 2015, pp. 927-928). Todo ello lleva a constatar que la Corte concibe el genocidio - principalmente- de manera abstracta. Esta visión también se confirma cuando la Corte afirma que: «it is difficult to establish such intent on the basis of isolated acts ${ }^{65}$. Como lo precisa el penalista alemán, para la Corte, la magnitud objetiva pareciera tener más importancia que la intención específica del perpetrador. Sin embargo, la Corte no justifica su preferencia por el enfoque «macro», lo que nos lleva a intuir que esa preferencia se explica en tanto se trata de un caso de responsabilidad del Estado y no individual (Behrens, 2015, pp. 928-929). Al respecto, debemos recalcar que en su opinión separada, el juez Skotnikov señaló la dificultad que enfrentaba la Corte al indagar sobre la intención específica, pues el Tribunal no tiene competencia penal y la inferencia de dicha intención solo le incumbe a un tribunal competente como el TPIY ${ }^{66}$. No obstante, y aun tomando ello en cuenta, la posición de la Corte no es convincente.

\footnotetext{
63 Véase también: Corte Internacional de Justicia. Application of the Convention on the Prevention and Punishment of the Crime of Genocide (Bosnia and Herzegovina v. Serbia and Montenegro). Reports, 2015. Opinión separada del juez Gaja, párr. 2.

64 Tribunal Penal Internacional para la Ex Yugoslavia. Prosecutorv. Goran Jelisic (Trial Judgement), IT-95-10-T, de 14 de diciembre de 1999, párr. 100.

65 Corte Internacional de Justicia. Application of the Convention on the Prevention and Punishment of the Crime of Genocide (Bosnia and Herzegovina v. Serbia and Montenegro). Reports, 2015, párr. 139.

66 Corte Internacional de Justicia. Application of the Convention on the Prevention and Punishment of the Crime of Genocide (Bosnia and Herzegovina v. Serbia and Montenegro). Reports, 2015, Opinión Separada del juez Skotnikov, párr. 10.
} 
La Comisión de Derecho Internacional, en sus Comentarios a los Artículos sobre la Responsabilidad del Estado por Hechos Internacionalmente Ilícitos, utilizó el ejemplo del genocidio como elemento subjetivo de atribución del ilícito y se desprende por tanto, que se podría requerir el conocimiento o la intención de agentes del estado o de órganos del mismo para atribuirles responsabilidad, sin tener que establecer previamente el carácter sistemático de una conducta ${ }^{67}$.

Behrens señala que es posible que, si la Corte hubiera aceptado utilizar, por lo menos parcialmente, el enfoque del perpetrador, se habría encontrado intención específica (2015 pp. 929-930). Ello se evidencia a la luz del criterio de sustancialidad cuya aplicación supone el análisis cuantitativo, cualitativo y geográfico de la parte del grupo atacado, para determinar si los perpetradores tenían la intención de destruir parte del grupo $^{68}$. El análisis cuantitativo toma en cuenta la parte del grupo atacado en relación con el grupo en su totalidad. El criterio cualitativo, analiza la prominencia de la parte del grupo atacado respecto a la totalidad del grupo; si la parte atacada tiene un valor emblemático o es tal, que el grupo no podría sobrevivir sin ella, podría ser una parte substancial del grupo. En cuanto al criterio geográfico, el penalista parte de la premisa de que la intención del perpetrador tiene un límite geográfico (una zona, un país, etc.) y por lo tanto, busca ponderar la sustancialidad, en relación tanto a la extensión de la zona bajo el control del perpetrador, como el nivel de alcance que tiene en la misma zona ${ }^{69}$. A la luz de todo ello, la Corte concluyó que los croatas de distintas zonas atacadas por fuerzas serbias constituían una parte sustancial del grupo protegido $^{70}$.

Según Behrens, el análisis de la extensión de la zona con relación al nivel de alcance del perpetrador constituye un «enfoque individualizado» (2015 pp. 923-925) que corresponde al enfoque en el perpetrador, previsto en la Convención, pero este no ha sido adoptado por la Corte. De haber sido este enfoque aplicado al criterio de oportunidad ${ }^{71}$

\footnotetext{
67 Véase: International Law Commissions. «Draft Articles on State Responsibility». En: YILC, 2001, volumen 2, parte II. Comentarios.

68 Corte Internacional de Justicia. Application of the Convention on the Prevention and Punishment of the Crime of Genocide (Bosnia and Herzegovina v. Serbia and Montenegro). Reports, 2015, párr. 931-937.

69 Tribunal Penal Internacional para la Ex Yugoslavia. Prosecutor v. Radislav Krstic (Appeal Judgement), IT-98-33-A, de 19 de abril de 2004, párr. 13. Estos criterios han sido aplicados en por la Corte en el caso que nos interesa. Véase Corte Internacional de Justicia. Application of the Convention on the Prevention and Punishment of the Crime of Genocide (Bosnia and Herzegovina v. Serbia and Montenegro). Reports, 2015, párr. 142 y 406.

70 Corte Internacional de Justicia. Application of the Convention on the Prevention and Punishment of the Crime of Genocide (Bosnia and Herzegovina v. Serbia and Montenegro). Reports, 2015, párr. 406.

71 Este criterio se fundamenta en un análisis de los hechos que busca determinar si el perpetrador ha aprovechado todas las oportunidades que se le presentaron para destruir los miembros del grupo. Corte Internacional de Justicia. Application of the Convention on the Prevention and Punishment of the Crime of Genocide (Bosnia and Herzegovina $v$. Serbia and Montenegro). Reports, 2015, párr. 431-437.
} 
(conexo al criterio de sustancialidad), es posible que se hubiera encontrado intención genocida. Este criterio supone que la intención genocida es limitada por las oportunidades que puede tener el perpetrador de cometer el delito de genocidio, por lo tanto, se trata de determinar si los perpetradores aprovecharon oportunidades para destruir partes sustanciales del grupo, lo que no pudo ser determinado en este caso $^{72}$. La Corte determinó respecto de Vukovar que se había demostrado que las fuerzas serbias no aprovecharon algunas oportunidades de destruir miembros del grupo protegido, lo que llevó la Corte a desestimar el criterio de oportunidad para determinar la intención específica ${ }^{73}$. Si bien la inferencia de la intencionalidad a partir de las oportunidades que aprovechó una organización en una zona geográfica específica es un método útil, un enfoque apegado al perpetrador podría ser más conforme al contexto: «circumstances go beyond geographical limitations and can show a significant degree of variation: A hundred victims may not fulfil substantiality' requirement in the eyes of the head of the armed forces. For a foot soldier, the killing of a hundred victims may be the most he could have done to effect the destruction of the group» (Behrens, 2015, p. 430) ${ }^{74}$.

El juez Bhandari ofreció varias críticas que apuntaban hacia la falta de análisis de hechos específicos. Recordó que en el Caso Tolimir ${ }^{75}$ (que se encontraba en apelación ante el TPIY durante las deliberaciones de la Corte) el TPIY determinó la existencia de genocidio por el asesinato de «únicamente» tres líderes prominentes de la comunidad de Zepa, en Bosnia. Además de ello, también criticó la decisión de la Corte por haber preferido no analizar el patrón sistemático de conductas, de manera general, y no haber abordado con detenimiento los ataques sistemáticos dirigidos hacia los croatas de Vukovar y sus alrededores ${ }^{76}$. Si bien el juez Bhandari no crítico directamente el carácter «macro» de la Corte dejó claro que abogaba a favor de un enfoque más aplicado a eventos y hechos específicos.

\footnotetext{
72 Idem.

73 Ibid., párr. 437.

74 Tribunal Penal Internacional para la Ex Yugoslavia. Prosecutor v. Radislav Krstic (Appeal Judgement), IT-98-33-A, de 19 de abril de 2004, párr. 13.

75 Tribunal Penal Internacional para la Ex Yugoslavia. Prosecutor v. Tolimir, (Trial Judgment), IT-05-88/2-T, de 12 de diciembre de 2012. En primera instancia, el caso fue apelado y la responsabilidad por genocidio del acusado fue desestimada pero subsistió la conclusión de que los hechos constituían genocidio. Véase Tribunal Penal Internacional para la Ex Yugoslavia. Prosecutorv. Tolimir, (Appeal Judgement), IT-05-88/2-A, de 8 de abril de 2015.

76 Corte Internacional de Justicia. Application of the Convention on the Prevention and Punishment of the Crime of Genocide (Bosnia and Herzegovina v. Serbia and Montenegro). Reports, 2015, Opinión Separada del juez Bhandari, párr. 40-50.
} 


\section{Conclusión}

Estos apuntes críticos al fallo de la Corte respecto de los distintos elementos subjetivos que configuran el delito de genocidio, ponen en cuestión el carácter limitativo del estándar inferencial y su interpretación en el caso Croacia vs. Serbia. Si bien la existencia de una pluralidad de elementos subjetivos no implicaba necesariamente que hubo intención genocida en este caso, esta diversidad ha sido tratada de manera inconsistente con los propios dictámenes de la Corte, y de manera cuestionable, de suerte a excluir la posibilidad que exista la intención genocida de manera concurrente a elementos subjetivos no genocidas.

Si bien este estándar tiene la virtud de pretender ser categórico, esta pretensión genera dudas respecto a la fundamentación de la imposible existencia de elementos subjetivos no genocidas junto a elementos genocidas. Este planteamiento pasa por alto la distinción entre motivo e intención, que ha sido discutida en varias ocasiones por la jurisprudencia de los tribunales penales internacionales y que habría servido de marco conceptual valedero para comprender — aunque parcialmente- la relación entre los distintos elementos subjetivos que se han presentado en este caso.

Esta limitación conceptual respecto a la intención genocida también se observa en la ausencia de una posición clara de la Corte frente a la realidad plural de la intención, que integra elementos volitivos y cognoscitivos.

En conclusión, dejamos abierta la pregunta sobre el rol de la Corte Internacional de Justicia en el desarrollo del concepto de genocidio y el respeto de la Convención. Es posible que la Corte haya adoptado un enfoque más abstracto, mientras que una aproximación que se enfoque en la perpetración de los supuestos actos genocidas habría sido más respetuosa del espíritu y la letra de la Convención. Pero tampoco se pueden soslayar las limitaciones que implica no ser un tribunal penal y es entendible que la Corte haya preferido el rol de un historiador que describe eventos de manera más general al rol de explorador del estado mental de los perpetradores (Behrens, 2015, p. 932). 


\section{Referencias bibliográficas}

Ambos, Kai (2009). What does «intent to destroy'» in genocide mean? International Review of the Red Cross, 91(876), diciembre. Disponible en: https://www.icrc.org/eng/resources/documents/article/review/review-876-p833.htm. http://dx.doi.org/10.2139/ssrn.1618682

Behrens, Paul (2015). Between Abstract Event and Individualized Crime: Genocidal Intent in the Case of Croatia. Leiden Journal of International Law, 28(4). http://dx.doi. org/10.1017/s0922156515000503

Behrens, Paul (2012). Genocide and the question of motives. Journal of International Criminal Justice, 10(3). http://dx.doi.org/10.1093/jicj/mqs038

Corte Internacional de Justicia (2007). Application of the Convention on the Prevention and Punishment of the Crime of Genocide (Bosnia and Herzegovina v. Serbia and Montenegro). Reports.

Corte Internacional de Justicia (2015). Application of the Convention on the Prevention and Punishment of the Crime of Genocide (Bosnia and Herzegovina v. Serbia and Montenegro). Reports.

Corte Penal Internacional (2010). Documentos oficiales de la Conferencia de Revisión del Estatuto de Roma de la Corte Pernal Internacional. RC/11. Kampala, 31 de mayo a 11 de junio de 2010.

Gil Gil, Alicia (1999). Derecho Penal internacional: especial consideración del delito de genocidio. Madrid: Tecnos.

Goldsmith, Katherine (2010). The Issue of Intent in the Genocide Convention and Its Effect on the Prevention and Punishment of the Crime of Genocide: Toward a KnowledgeBased Approach. Genocide Studies and Prevention: An International Journal, 5(3). http://dx.doi.org/10.3138/gsp.5.3.238

Greenawalt, Alexander K.A. (1999). Rethinking genocidal intent: the case for a knowledgebased interpretation. Columbia Law Review, 99. DOI: 10.2307/1123611.

International Law Commissions (2001). Draft Articles on State Responsibility. Year Book of International Law Commission, 2, parte II. Comentarios.

Kirsch, Stefan (2009). The Two Notions of Genocide: Distinguishing Macro Phenomena and Individual Misconduct. Creighton Law Review, 42. http://dx.doi.org/10.1007/ 978-90-6704-567-4_11

Kress, Claus (2005). The Darfur Report and Genocidal Intent. Journal of International Criminal Justice, 3. http://dx.doi.org/10.1093/jicj/mqi054

Manashaw, Linnea D. (2004). Genocide and ethnic cleansing: why the distinction a Discussion in the context of atrocities occurring in Sudan. Californian Western International Law, 35(2).

Munivrana Vajda, Maja (2015). Ethnic Cleansing as Genocide - Assessing the Croatian Genocide Case before the ICJ. International Criminal Law Review, 15(1). DOI: 10.1163/ 15718123-01406010.

Naciones Unidas (1948). Convention on the Prevention and Punishment of the Crime of Genocide. De 9 de diciembre. En Treaty Series, 78, p. 277, artículo II. Disponible en: http://www.refworld.org/docid/3ae6b3ac0.html 
Naciones Unidas (1948). Official Records of the Third Session of the General Assembly, Part I. Legal Questions, Sixth Committee. Summary Records of Meetings, 21 de setiembre - 10 de diciembre. Doc. A/C.6/SR.75.

Schabas, William A. (2009). Genocide in International Law: The Crime of Crimes. Segunda edición. Cambridge: Cambridge University Press. http://dx.doi.org/10.1017/cbo978 0511575556

Tribunal Penal Internacional para la ex Yugoslavia (1999). Prosecutor v. Goran Jelisic (Trial Judgement), IT-95-10-T, de 14 de diciembre.

Tribunal Penal Internacional para la ex Yugoslavia (1999). Prosecutor v. Dusko Tadic (Appeal Judgement), IT-94-1-A, de 15 de julio.

Tribunal Penal Internacional para la ex Yugoslavia (1999). The Prosecutor v. Clément Kayishema and Obed Ruzindana (Trial Judgement), ICTR-95-1-T, de 21 de mayo.

Tribunal Penal Internacional para la ex Yugoslavia (2001). Prosecutor v. Goran Jelisic (Appeal Judgement), IT-95-10-A, de 5 de julio.

Tribunal Penal Internacional para la ex Yugoslavia (2001). Prosecutor v. Dragoljub Kunarac, Radomir Kovac and Zoran Vukovic (Trial Judgment), IT-96-23-T \& IT-96-23/1-T, de 22 de febrero.

Tribunal Penal Internacional para la ex Yugoslavia (2003). Prosecutor v. Milorad Krnojelac (Appeal Judgement), IT-97-25-A, de 17 de setiembre.

Tribunal Penal Internacional para la ex Yugoslavia (2004). Prosecutor v. Tihomir Blaskic (Appeal Judgement), IT-95-14-A, de 29 de julio.

Tribunal Penal Internacional para la ex Yugoslavia (2004). Prosecutor v. Radislav Krstic (Appeal Judgement), IT-98-33-A, de 19 de abril.

Tribunal Penal Internacional para la ex Yugoslavia (2006). Prosecutor v. Milomir Stakic (Appeal Judgement), IT-97-24-A, de 22 de marzo.

Tribunal Penal Internacional para la ex Yugoslavia (2007). Prosecutor v. Mrksic et al. (Trial Judgment), IT-95-13/1-T, de 27 de setiembre.

Tribunal Penal Internacional para la ex Yugoslavia (2012). Prosecutorv. Tolimir, (Trial Judgment), IT-05-88/2-T, de 12 de diciembre.

Tribunal Penal Internacional para la ex Yugoslavia (2015). Prosecutor v. Tolimir, (Appeal Judgement), IT-05-88/2-A, de 8 de abril.

Tribunal Penal Internacional para la ex Yugoslavia (2015). Prosecutor v. Vujadin Popovic (Appeal), IT-05-88-A, de 30 de enero.

Villavicencio Terreros, Felipe (2013). Derecho Penal: Parte General. Lima: Grijley.

Zivkovic, Tara (2015). An Impossible Standard of Intent?: Croatia $v$. Serbia at the International Court of Justice. The Yale Journal of International Law, 40.

Fecha de recepción: 7 de marzo de 2016

Fecha de aprobación: 29 de abril de 2016 